Esta obra forma parte del acervo de la Biblioteca Jurídica Virtual del Instituto de Investigaciones Jurídicas de la UNAM www.juridicas.unam.mx

\title{
EL DESARROLLO Y LA REgULACIÓN DEL MODELO NORTEAMERICANO DE PUBLICIDAD POLÍTICA TELEVISADA CON REFERENCIA A LA ELECCIÓN PRESIDENCIAL MEXICANA DEL AÑO 2000
}

Francisco José de ANDREA SÁNCHEZ ${ }^{1}$

\section{Sumario:}

I. Panorama general

II. Una clasificación de los tipos y las funciones de los comerciales políticos

III. Las tres grandes funciones retóricas de los comerciales políticos televisados

RESUMEN: El presente ensayo versará sobre la teoría, el uso y las funciones de la publicidad política televisada en el derecho comparado con especial referencia al caso de la elección presidencial de la llamada "alternancia o transición" que tuvo lugar en el 2000 y que desde nuestro punto de vista constituye un parteaguas en la utilización abierta, sofisticada, estratégica y en ese entonces aún no regulada de la publicidad político-electoral televisada.

Palabras clave: derecho electoral, campañas políticas, propaganda política, elecciones.

ABSTRACT: This essay deals with the theoretical and practical aspects of televised political adds with special reference to the Presidential Election held in Mexico in 2000 which represents a key turning point in subject matter in Mexico.

Keywords: elections, political campaigns, political adds, election law.

\section{PANORAMA GENERAL}

Debemos destacar, llevando agua a nuestro molino, que existen seis factores que justifican y hacen relevante el presente artículo para el derecho electoral mexicano actual y que son:

\footnotetext{
${ }^{1}$ Investigador del Instituto de Investigaciones Jurídicas de la UNAM
} 
Esta obra forma parte del acervo de la Biblioteca Jurídica Virtual del Instituto de Investigaciones Jurídicas de la UNAM

1. Desde el punto de vista de la pertinencia de un estudio de historia electoral, los 14 años que han pasado desde el 2000 constituyen un periodo suficientemente largo para analizar de manera desapasionada y con base en un cuerpo robusto de enfoques multidisciplinarios la elección presidencial de la alternancia;

2. Es la primera elección presidencial mexicana en la que las estrategias contemporáneas de ataque mediático se presentan de manera planeada, sofisticada y efectiva en los enfrentamientos de Vicente Fox con Francisco Labastida Ochoa y del primero con Cuauhtémoc Cárdenas, puesto que en 1994 las estrategias de ataque mediático de Diego Fernández de Cevallos contra Zedillo y Cárdenas a la postre no afectaron el resultado final que arrojó una victoria para Ernesto Zedillo;

3. El desarrollo del enfrentamiento al interior del PRI entre Roberto Madrazo y Francisco Labastida determinó la actitud del propio Roberto Madrazo en la elección general presidencial del 2006;

4. La elección presidencial del 2000 es la clave del proceso electoral para entender el mapa de los procesos y las reformas político-electorales en México en los últimos 20 años en tanto que la dinámica interna que se observó en el PAN a partir de 1998 con el secuestro de la candidatura presidencial de dicho partido por parte de Vicente Fox -anulando los procesos internos tradicionales de selección de candidatos del PANrepercutió no sólo en los documentos básicos del PAN sino en la legislación electoral federal mexicana;

5. Por otro lado, el uso y abuso del financiamiento paralelo -en aquel entonces no regulado detalladamente en la legislación electoral mexicana- del cual se benefició Fox y que constituye la clave de su victoria electoral también fue un fenómeno de profundo impacto en las estructuras e instituciones electorales mexicanas, en especial en materia de campañas políticas positivas y negativas;

6. Asimismo, el desempeño de Cuauhtémoc Cárdenas en el proceso electoral del 2000 abrió las puertas a la primera candidatura de Andrés Manuel López Obrador lo que evidentemente también ha tenido un impacto de gran relevancia en la evolución de la política y las elecciones en México, y la regulación de los conceptos de denigración y calumnia referidos a la publicidad positiva y negativa en México.

Ahora bien, ya entrando de lleno en esta temática y con una visión retrospectiva, se aprecia claramente que a partir de que Roberto Madrazo escogió teñir sus 
Esta obra forma parte del acervo de la Biblioteca Jurídica Virtual del Instituto de Investigaciones Jurídicas de la UNAM

promocionales televisados durante la contienda interna al interior del PRI por la candidatura presidencial del 2000, con una dinámica confrontacional de "ataque", se emitió una señal de alerta que obligaría al equipo de campaña de Francisco Labastida Ochoa a perfilar una estrategia de "respuesta" y defensa a dicha línea de enfrentamiento, la cual sólo se fue profundizando a lo largo del proceso de selección interna del candidato presidencial del PRI en vísperas de la elección del 2000, por lo que cabe señalar de manera muy precisa, colocó desde nuestro punto de vista en ese preciso momento a Francisco Labastida Ochoa en una espiral descendente defensiva que como atestiguamos en su momento continuó una vez superado el reto de Madrazo al interior del PRI y se profundizó ya en plena elección general como un abanderado del partido previamente debilitado, fatigado y a la defensiva ante un candidato paradigmáticamente agresivo como lo fue Vicente Fox a lo largo de la campaña presidencial del 2000.

En el anterior sentido, se hace necesario realizar una revisión y un análisis del estado de los conocimientos especializados en la materia de los comerciales, promocionales o "spots" de campañas políticas a nivel comparado que permita analizar las estrategias de campaña de Francisco Labastida Ochoa tanto en la referida contienda interna del PRI como en la elección general frente a Vicente Fox y Cuauhtémoc Cárdenas. El arsenal de ideas, sugerencias, conceptos y técnicas resumidas en este ensayo pueden ser de utilidad tanto en la fase interna de una campaña política, como en una elección general; al igual que una novela tiene ciertas normas - preceptiva literaria - elementales sobre su estructura, tiempos y desarrollo, sin los cuales carecería de calidad y éxito mediático, también una campaña político-electoral publicitaria en la televisión y el ciberespacio debe observar ciertas pautas y ritmos, so pena de "errarse" el camino.

\section{UNA CLASIFICACIÓN DE LOS TIPOS Y LAS FUNCIONES DE LOS COMERCIALES POLÍTICOS}

\section{Las 4 fases esenciales de la publicidad política}

En los últimos 20 años se ha incrementado el número de comerciales políticos televisados utilizados durante las campañas electorales a nivel mundial, y también se ha incrementado notablemente el número de "especialistas" que escriben superficialmente o con profundidad-, o hablan, seria o frívolamente, respecto a los mismos. Así, ya sea que se trate del informe de un consultor u operador práctico, o del análisis de un académico, todas estas opiniones han contribuido a otorgarle una 
Esta obra forma parte del acervo de la Biblioteca Jurídica Virtual del Instituto de Investigaciones Jurídicas de la UNAM www.juridicas.unam.mx

descripción conceptual a los comerciales políticos usados en la actualidad. Por ejemplo, algunos autores argumentan que la publicidad política — sin importar sistema político o país- atraviesa por al menos cinco fases, y, por lo tanto, produce cinco tipos de comerciales. $^{2}$

La primera etapa, se caracteriza por los llamados comerciales de identidad que son aquellos promocionales con un tinte netamente biográfico y cuya intención es introducir o identificar al candidato - proveer una clave sobre la personalidad del candidato- en las fases iniciales de una elección primaria o de una campaña en una elección general. ${ }^{3}$

La segunda etapa tiene como resultado, la producción de los llamados comerciales argumentativos, los cuales identifican las causas, las ideas, y las preocupaciones del candidato, en pocas palabras, el basamento fundamental en que se apoya un candidato determinado. ${ }^{4}$

La tercera etapa se da con los llamados comerciales de ataque (modalidad del género de los comerciales negativos) que constituyen ataques directos y personales, cuyo objetivo es reducir la credibilidad del candidato rival u opositor - crear dudas, provocar temores y miedos, explotar la ansiedad, o motivar el ridículo-. Un ejemplo paradigmático de este tipo de comerciales fue la campaña orquestada en México por el PAN en la elección presidencial del 2006 presentando a Andrés Manuel López Obrador como un peligro para México. ${ }^{5}$

La cuarta etapa produce los llamados comerciales visionarios que son utilizados cuando la campaña política se acerca a su cierre, con el fin de proveer una visión reflexiva y razonada de los candidatos para generar la impresión de que el candidato tiene una habilidad o capacidad de liderazgo y la visión para conducir al país hacia adelante.

\footnotetext{
2 Diamond, Murray, The Spot: The Rise of Political Advertising on Television, Cambridge, MIT Press, 1988, pp. 293-340.

${ }^{3}$ Idem.

${ }^{4}$ Idem.

5 En este sentido véase, http://www.animalpolitico.com/2012/09/el-eslogan-un-peligro-para-mexicopersiguio-a-amlo-hasta-2012-parametria/\#axzz2nOSlab11 y http://Www.youtube.com/watch?v=zXCUOHDJ7Wk
} 
Esta obra forma parte del acervo de la Biblioteca Jurídica Virtual del Instituto de Investigaciones Jurídicas de la UNAM www.juridicas.unam.mx

DOI: http://dx.doi.org/10.22201/iij.24487910e_2015.7.10085

Por último, en quinto lugar identificamos a los llamados comerciales de aniquilamiento que pretenden dar una estocada mortal a un rival electoral mediante la publicitación ya sea a través de comerciales formales o de declaraciones en debates de hechos o acontecimientos tan escandalosos y graves que usualmente sepultan toda posibilidad de triunfo electoral a partir de su divulgación. Tales son los casos de la revelación de Roberto Campa Cifrián sobre las irregularidades fiscales de Roberto Madrazo Pintado en los debates previos a la elección presidencial del $2006 .{ }^{6}$ Los comerciales de aniquilamiento usualmente se presentan a semanas o pocos meses de la celebración de los comicios de que se trate para lograr un efecto de frescura en la mente del electorado que ocasione el mayor daño electoral y mediático posible a sus rivales.

\section{Análisis de los comerciales de publicidad televisada de campañas}

presidenciales en los Estados Unidos de Norteamérica

de 1952 a 1980

En un análisis ya clásico de los comerciales televisivos en campañas presidenciales norteamericanas utilizados desde 1952 hasta 1980, Patrick Devlin ${ }^{7}$ describe los comerciales políticos en términos de las siguientes categorías: (a) talking head adds que son los comerciales de "cabezas parlantes", o en términos más accesibles comerciales en los que el punto focal del comercial es la cara de un individuo que expresa algún punto de vista; (b) comerciales negativos que son aquellos comerciales que destrozan al opositor; (c) comerciales de cinema verité, como aquellos en los cuales el candidato es filmado en una ocasión o ubicación de la vida real interactuando con personas reales; (d) comerciales documentales y/o promocionales que presentan los logros del candidato; (e) comerciales del "hombre común" u "hombre de la calle" como aquellos en los cuales personas de la vida real hablan positivamente sobre un candidato o partido político o bien negativamente sobre un adversario político o causa política; (f) comerciales testimoniales en los cuales, personas prominentes o famosas hablan en favor del candidato, y (g) comerciales independientes como aquellos que son patrocinados por organizaciones formal y materialmente independientes del candidato de que se trate.

\footnotetext{
${ }^{6}$ http://Www.proceso.com.mx/?p=217108

7 Devlin, Patrick, "An Analysis of Presidential Television Commercials, 1952-1984," en Lee Kaid, Lynda et al; New Perspectives on Political Advertising, Carbondale, Edwardsville, Southern Illinois University Press, 1986, pp. 21-50.
} 
Esta obra forma parte del acervo de la Biblioteca Jurídica Virtual del Instituto de Investigaciones Jurídicas de la UNAM www.juridicas.unam.mx

\section{El arquetipo del "líder benévolo": el modelo prevaleciente}

en un estudio de comerciales políticos televisados

En un estudio de la publicidad política y su significado en las elecciones norteamericanas, Richard Joslyn ${ }^{8}$ identificó cuatro distintas perspectivas a través de las cuales se pueden entender los procesos electorales contemporáneos y argumenta que bajo cada perspectiva se utilizan distintos tipos de arquetipos que enganchan la atención del elector en los comerciales o propaganda televisada. Así, y después de haber examinado cientos de dichos comerciales políticos, descubrió que el tipo de comerciales más frecuente es aquel que él caracterizó como el del líder benévolo. Los comerciales de líder benévolo, según el autor, se enfocan sobre las características de la personalidad del candidato por encima de acciones programáticas, posiciones de política, valores políticos e “intentan lograr una correspondencia lógica entre las expectativas del papel de un puesto de elección popular y las características de la persona del propio candidato." ${ }^{9}$

Por ejemplo, los comerciales pertenecientes a la categoría del líder benévolo pueden enfocarse sobre las siguientes características de un candidato político: (a) la valentía personal; (b) la honestidad; (c) la fuerza de personalidad y carácter; (d) un sentido de la equidad y la justicia; (e) la compasión, y (f) la perseverancia. Tal listado de virtudes, por ejemplo, sólo se encuentran en un caso paradigmático de la vida real contemporánea en el líder benévolo por antonomasia que en la actualidad fue Nelson Mandela.

Ahora bien, los citados comerciales pueden ser producidos en forma de reportajes biográficos o de documentales en los cuales el candidato es mostrado en situaciones en las que las características arriba señaladas son evidentes, o en testimoniales en los cuales una persona prominente discurre sobre una característica específica de un candidato, o incluso bajo el formato del hombre común de la calle y en el cual un número de personas determinado son presentadas en el comercial haciendo comentarios respecto a las virtudes del candidato. Cualquiera que sea la forma que adopte el comercial de tipo "líder benévolo", su enfoque principal son las características o fortalezas de carácter y personalidad del candidato. En México, el prototipo de líder benévolo, de benefactor nacional fue encarnado por Lázaro Cárdenas de manera tan

\footnotetext{
${ }^{8}$ Joslyn, Richard, “Political Avertising and the Meaning of Elections", en Lee Kaid, Lynda, New Perspectives on Political Advertising, Carbondale and Edwardsville, SIU Press, 1986, pp.139-80.

${ }^{9}$ Idem.
} 
Esta obra forma parte del acervo de la Biblioteca Jurídica Virtual del Instituto de Investigaciones Jurídicas de la UNAM

efectiva, que en gran parte este encanto alcanzó décadas después para beneficiar a sus descendientes.

\section{Los subtipos de comerciales negativos}

Por otra parte, los académicos no sólo han ofrecido un esquema de clasificación para agrupar los comerciales televisados, algunos incluso han sugerido que los comerciales negativos pueden, a su vez, dividirse en subtipos específicos. Kathleen Hall Jamieson, ${ }^{10}$ ha sugerido que existen tres tipos fundamentales de comerciales negativos que ella define como (a) comerciales conceptuales siendo aquellos que yuxtaponen imágenes visuales no relacionadas para sugerir inferencias falsas); (b) comerciales con testimonios personales que presentan a ciudadanos comunes y corrientes haciendo declaraciones espontáneas negativas espontáneas respecto al opositor, y (c) comerciales con reporteros o entrevistadores neutrales como aquellos en los cuales una serie de afirmaciones informativas son presentadas para que entonces el elector sea invitado a realizar un juicio de valor o a sacar una conclusión sobre el oponente en un escenario de aparente naturalidad y espontaneidad.

Ahora bien, aunque este resumen ciertamente no es exhaustivo, sí puede auxiliar en la apreciación de la complejidad inherente de los intentos por tratar de entender y distinguir entre los distintos tipos de comerciales televisados que han sido utilizados comparativamente en distintos países desde 1952.

Sin embargo, cabe aclarar que nuestra intención final no es contribuir ni a la proliferación de las tipologías de los comerciales, ni a la dificultad intrínseca en la descripción contemporánea de la publicidad política.

Antes, al contrario, nuestra meta teórica y práctica en este ensayo es reducir la ambigüedad existente respecto al tema, mediante la clasificación de comerciales según su propósito narrativo y retórico principal.

Así, dentro de cada categoría hacemos subdivisiones únicamente en términos de factores del "estilo de video" (contenido verbal, contenido no-verbal, técnicas de producción cinematográfica-video o digital, vía Youtube.com) que parecen tener características lo suficientemente significativas como para distinguirlas unas de otras.

\footnotetext{
${ }^{10}$ Hall Jamieson, Kathleen, "The Evolution of Political Advertising in America”, Nueva York, Oxford University Press, 1984, pp.17 y 18.
} 
Esta obra forma parte del acervo de la Biblioteca Jurídica Virtual del Instituto de Investigaciones Jurídicas de la UNAM

Ahora bien, nuestra sugerencia o aportación fundamental en este ensayo es la idea de que una de las razones para clasificar los tipos de comerciales políticos televisados, es obtener un entendimiento cabal de su propósito narrativo y retórico profundo.

En el anterior sentido, si bien los comerciales políticos son utilizados por los candidatos políticos para realizar una variedad de funciones, éstos tienen tres propósitos retóricos fundamentales: (a) el alabar o fortalecer al candidato; (b) el condenar o vilipendiar al adversario, y (c) o responder directamente o indirectamente según sea conveniente estratégicamente a ataques o impugnaciones.

Así, aunque de tiempo en tiempo estos propósitos o metas puedan mezclarse, los comerciales políticos esencialmente pueden ser entendidos en términos de sus propósitos retóricos primarios.

\section{LAS TRES GRANDES FUNCIONES RETÓRICAS DE LOS COMERCIALES POLÍTICOS TELEVISADOS}

\section{Comerciales que enfatizan las virtudes}

de un candidato político

Los elementos del llamado video-estilo disponible para ser utilizado en aquellos comerciales cuyo propósito fundamental es alabar al candidato son virtualmente ilimitados. A través de los años se han utilizado diversas técnicas, tales como el testimonio, los documentales, las "cabezas parlantes", el llamado cinema verité, el "hombre de la calle", los eslóganes, las plataformas, o el líder benévolo. Claro está, en algunos años electorales y en algunas campañas, algunos candidatos se han apoyado de manera extensa sobre algún tipo particular de video-estilo, por ejemplo, en 1980, la mayoría de los comerciales televisados de Ronald Reagan fueron comerciales documentales.

La mayoría de las campañas que disponen de los recursos financieros para hacerlo, utilizan una variedad de estilos para promocionar las virtudes y/o fortalezas de su candidato. Es importante, sin embargo, que el video estilo no debilite o mine el objetivo principal del comercial —alabar al candidato e ignorar al oponente-.

Las funciones comunicativas realizadas a través de los comerciales políticos con la arriba citada naturaleza, son tan variadas como los propios video-estilos. A mayor abundamiento, tienen una naturaleza realmente crítica tanto para los representantes políticos en activo que buscan reelegirse como para quienes buscan desbancarlos o 
Esta obra forma parte del acervo de la Biblioteca Jurídica Virtual del Instituto de Investigaciones Jurídicas de la UNAM

evitar su reelección, aunque el grado en el cual son utilizados puede variar en relación con otras condiciones.

En este sentido, en la elección presidencial mexicana del 2000 no se cuidó el encasillamiento o la formación de un estereotipo o modelo de imagen creado por sus opositores para Francisco Labastida Ochoa, cuyo equipo de estrategia mediática careció de la suficiente flexibilidad para poder adaptar su imagen electoral (contenida en publicidad o comerciales políticos) a condiciones y circunstancias cambiantes que se presentaron en los comicios de julio del 2000, como fueron las burlas tanto de Madrazo -en la fase de la selección interna- como de Vicente Fox Quesada ya en la elección general; esto es, las características y el estilo de la imagen de Francisco Labastida Ochoa debieron ser tales que permitieran maniobrar, modificar y moldear dicha imagen de manera eficaz en la elección; de esta forma, se le colocó una suerte de "camisa de fuerza publicitaria" a la imagen de Francisco Labastida Ochoa que le restó posibilidades de frescura en la etapa de la elección general.

Por ejemplo, de gran relevancia y actualidad para el derecho electoral mexicano vigente a partir de la reforma de 2013-2014, que consagra la figura de la reelección legislativa consecutiva que entrará en vigor en el 2015, si un candidato es un político desconocido contendiendo contra un político en activo que busca reelegirse, es de crítica importancia que la campaña -en general- emita el mensaje esencial del citado candidato. En otras palabras, que el comercial provea información sobre sus antecedentes, logros, posiciones respecto a los grandes temas nacionales, sus fortalezas de carácter y personalidad, su familia y asociados -todo lo cual, define finalmente al candidato.

En este sentido, los comerciales tanto televisados, como crecientemente a través de redes sociales y canales como Youtube.com, pueden llevar a cabo esta función con gran rapidez que la mayor parte de las herramientas o instrumentos tradicionales de campaña restantes y disponibles para un candidato, y su equipo de campaña.

Ahora bien, aunque existen ejemplos numerosos de candidatos políticos -aspirantes a todos los niveles - que hayan tenido éxito al utilizar únicamente comerciales de este tipo para "definirse" a sí mismos ante el electorado, no es fácil recordar uno que realmente lo haya logrado. 
Esta obra forma parte del acervo de la Biblioteca Jurídica Virtual del Instituto de Investigaciones Jurídicas de la UNAM

De esta forma, en la elección presidencial norteamericana de 1988, Michael Dukakis no se movió lo suficientemente rápido -en este caso, el que se mueve si sale en la fotodespués de la Convención de Nominación Democrática para decirle al público elector quien era él, cuál era su plataforma, cuáles habían sido sus logros, y por qué él debía ser presidente.

Como consecuencia de lo anterior, la primera serie de comerciales transmitidos en la campaña de Bush padre -inmediatamente después de la Convención Nacional Republicana - Ilenaron dicho vacío y proveyeron la definición faltante de la personalidad de imagen de Dukakis; el problema obvio para el candidato de los Demócratas fue por supuesto, que la definición republicana no era muy halagadora.

Cabe tener en mente el anterior ejemplo en México para recordar que la definición y el estereotipo de la imagen de Francisco Labastida Ochoa en el lapso de 1999 a 2000 fueron en gran parte fraguados por la imagen que de él pintó Fox, quien llenó el vacío que debió ocupar el propio Labastida y su equipo de campaña que no supieron brindar una inyección de frescura de imagen a su candidatura.

Una segunda función de gran importancia realizada por los comerciales de referencia, incluye la utilización de promocionales para desarrollar y explicar la posición y postura de un candidato sobre los grandes temas nacionales del momento.

En el sentido anterior, la televisión no únicamente se ha convertido en la fuente aún primaria de información para la mayoría de la población en México sino que también se da el caso de que los comerciales políticos se han convertido en sí mismos en una fuente primordial de información electoral respecto a todos los aspectos de una campaña.

Como lo ha demostrado la investigación comparada en la materia de comerciales político-electorales, los electores pueden aprender más sobre la posición o postura de un candidato respecto a una cuestión o tema nacional de lo que observan en un comercial, de lo que pueden aprender observando los noticiarios de la noche, en especial si los medios constituyen una parte interesada en la victoria o derrota de algunos de los candidatos en una elección.

A mayor abundamiento, los comerciales tienen un efecto acumulativo, en el sentido de que su repetición frecuente durante el lapso de una campaña electoral auxilia a los electores en su aprendizaje sobre la postura de un candidato sobre un asunto o cuestión determinada. 
Esta obra forma parte del acervo de la Biblioteca Jurídica Virtual del Instituto de Investigaciones Jurídicas de la UNAM

Algunas otras funciones adicionales y relacionadas llevadas a cabo por los comerciales que alaban las virtudes de un candidato incluyen:

(a) Un reforzamiento de los sentimientos positivos de los simpatizantes y partidarios pues el único hecho de observar un comercial sobre el candidato de nuestra elección, puede fortalecer la convicción de la causa o bien de la selección de éste, y pensar que es la adecuada;

(b) La redefinición o suavizamiento de la imagen de un candidato como en 1968, cuando la imagen de Richard Nixon como un modelo de "perdedor en la vida" fue redefinida, para presentarlo como "un estadista," en gran parte gracias a sus comerciales televisados. Y qué decir en el caso que se dio en 1976 de la imagen de Gerald Ford como un bufón bien intencionado, que fue redefinida para presentar a un hombre presidenciable, gracias al genio y originalidad de un comercial político que giraba en torno a la idea central que llevaba como lema, la frase: "me siento bien respecto a América".

(c) Y la obtención de fondos, como lo que pasó en 1984, cuando los Demócratas utilizaron un comercial especial de 5 minutos sobre Walter Mondale, con el fin de obtener fondos de simpatizantes para entonces poder difundir comerciales posteriores.

En resumen, los comerciales políticos cuyo propósito es "alabar" al candidato realizan funciones muy importantes para el éxito de una campaña electoral.

\section{Los comerciales políticos que condenan, atacan}

\section{o cuestionan al adversario}

Así como pueden ser utilizadas una gran variedad de elementos de la modalidad de comerciales video grabados que enfatizan las virtudes de un candidato, igualmente existen un gran número de distintas y variadas técnicas que son utilizadas en comerciales que se enfocan fundamentalmente sobre el oponente, adversario o rival político.

Por ejemplo, las campañas políticas contemporáneas a nivel comparado han utilizado estilos o variaciones tales como: (a) la asociación o conceptualización negativa; (b) la comparación; (c) el testimonio personal; (d) la llamada "cabeza parlante"; (e) el ataque; (f) el cinema verité, y (g) el aniquilamiento. 
Esta obra forma parte del acervo de la Biblioteca Jurídica Virtual del Instituto de Investigaciones Jurídicas de la UNAM

Aunque los factores de la modalidad de comerciales video grabados pueden variar, y por lo tanto, alterar la fortaleza y contundencia de un ataque, el propósito primario no variará. Así, estos son comerciales diseñados para colocar al adversario bajo una luz desfavorable o en una posición incómoda. Se enfocan sobre las desventajas reales o imaginadas del rival más que sobre los atributos del candidato propio.

En el sentido más amplio, el propósito de este tipo de comerciales — sin importar la variedad de técnicas empleadas - es incrementar los "aspectos netamente negativos" del adversario. En este sentido, una buena dosis de morbo y su efectividad han hecho que este tipo de comerciales hayan recibido mucha atención del público elector, así como de columnistas y académicos especializados en su estudio.

Por tanto, desde la introducción de los comerciales televisados en los Estados Unidos de Norteamérica a principios de los años 50 del siglo pasado, cuyo propósito era atacar al rival político, ha sido desarrollada una gran gama de formatos y estrategias.

Algunos comerciales han utilizado el (a) sentido del humor; (b) el factor del ridículo; (c) el estado de salud del rival; (d) han asociado al adversario con cuestiones altamente impopulares (el caso muy acertado del comercial sobre la venta de Pemex de Roberto Madrazo hecha ante extranjeros), o con personas negativamente apreciadas por el público elector (culpabilidad por asociación), este fue el caso, por ejemplo en el periodo (1999-2000) de la fuerte asociación de la imagen de Madrazo con Cabal Peniche; (e) algunos otros comerciales han utilizado o colocado membretes sobre sus adversarios y posteriormente han definido dichos membretes de manera negativa; ( $f$ ) otros más, se han apoyado en la utilización del miedo y del temor, y (g) han buscado crear sospechas sobre las creencias o acciones previas de un opositor (en este sentido, las escenas de violencia de golpeadores utilizados por el equipo de Madrazo previamente a su toma de protesta en Tabasco ${ }^{11}$ buscaban despertar subliminalmente un temor en el electorado mexicano a un ambiente de violencia enrarecido asociado a Madrazo).

Por otra parte, ocasionalmente al telespectador se le expone a técnicas que inducen al electorado a tomar partido en cierta dirección, esto es, el ataque o la condenación es implicada (técnica muy usada por Madrazo en "Crimen y Castigo"). Igualmente, los $h$ 
Esta obra forma parte del acervo de la Biblioteca Jurídica Virtual del Instituto de Investigaciones Jurídicas de la UNAM

antecedentes de un candidato y de su adversario son comparados para que parezca que éste carece de atributos o virtudes. Sin embargo, cabe aclarar que usualmente no se utilizan los ataques o las acusaciones directas ni las afirmaciones conducidas, para evitar complicaciones jurídicas posteriores en casos de demandas por difamación o calumnia.

En otras instancias, el ataque puede ser directo y abierto. Por ejemplo, ya sea en la narrativa o con el uso de símbolos visuales o auditivos a los telespectadores se les informa sobre las desventajas y debilidades del opositor. Claramente, y dependiendo del estilo escogido y por supuesto de la intención, los comerciales políticos ubicados bajo esta categoría pueden variar considerablemente.

De esta forma, se les ha dado nombre y concepto a dos de los comerciales más y se les ha diferenciado entre sí en términos de lo que se ubica como sus estrategias de estilo de producción y formato fundamentalmente. Estos son los llamados comerciales de "venta suave", comerciales que hacen un uso fundamental muy fuerte de algunos valores del mundo del entretenimiento ligero, del humor, del relato de historias inocuas, y aquellos comerciales llamados "de venta dura" que utilizan colores oscuros, voces amenazantes y crean una sensación de fatalidad, y tragedia inminentes.

Este tipo de comerciales fue ampliamente utilizado en las campañas políticas panistas en México en las elecciones presidenciales de 2006 y 2012, y se apoyaban fundamentalmente de símbolos auditivos y visuales para crear reacciones emotivas y de gran intensidad tales como el enojo, el miedo, la incertidumbre, la ansiedad o las sospechas.

Sin lugar a dudas, el uso extendido de comerciales con una alta carga de ataque o condena continuará en las campañas políticas mexicanas futuras. De hecho, los comerciales negativos utilizados por Calderón en 2006 y Vázquez Mota en 2012, fueron difundidos y transmitidos de manera tan frecuente y tuvieron tal impacto que parte importante de la condena del público elector hacia la figura de López Obrador, provino inicialmente de estos comerciales, y de algunos columnistas y académicos que retomaron dicha carga negativa.

\section{Las funciones comunicadoras de los comerciales}

políticos de ataque

En general, las funciones de comunicación de los comerciales de ataque son bastante claras: (a) si un candidato utiliza comerciales de ataque al inicio de su campaña y si son 
Esta obra forma parte del acervo de la Biblioteca Jurídica Virtual del Instituto de Investigaciones Jurídicas de la UNAM

DOl: http://dx.doi.org/10.22201/iij_24487910e_2015.7.10085

transmitidos con la suficiente frecuencia, pueden establecer la agenda retórica para el adversario u opositor, que de alguna manera tendrá que responder, y se constituirá involuntariamente en rehén de dicha dinámica; (b) una segunda función de los comerciales de ataque, es que pueden obligar a adoptar una postura defensiva incluso en un candidato agresivo y por lo tanto reducir el tiempo, la meditación, y los recursos financieros que pueden ser distribuidos para presentar una imagen positiva, y (c) igualmente, y quizás más aparente en campañas políticas recientes, el uso de comerciales de ataque o condena (si los ataques se enraízan en la mente del público elector) pueden hacer, comparativamente, que un candidato mediocre se vea por momentos mejor que el opositor o adversario.

En otras palabras, usando la terminología de los consultores políticos a nivel mundial, los candidatos políticos deben siempre intentar reducir sus puntos negativos y construir sobre los positivos de ellos mismos al incrementar los puntos negativos de sus adversarios, ya sean éstos reales o imaginarios.

El uso de comerciales de ataque también puede ayudar a un candidato a contribuir a la percepción de que son individuos intrínsecamente fuertes o decisivos aunque no lo sean en su propia realidad existencial.

Por otro lado, y finalmente, el empleo de los comerciales de ataque puede funcionar para desviar la atención pública de aquellas cuestiones que puedan amenazar a un candidato o que puedan constituir fuente de situaciones potencialmente embarazosas. En otras palabras, pueden servir para conservar el enfoque de una campaña sobre las áreas de fortaleza de un candidato evitando sus áreas de vulnerabilidad, inoculando al candidato vulnerable mediante la distracción de la atención mediática.

\section{Los comerciales políticos que responden a ataques}

\section{o insinuaciones malsanas}

Hasta muy recientemente, se había escrito muy poco en la literatura electoral comparada sobre esta última categoría de la publicidad política televisada. Pero como en el caso de los otros dos tipos anteriores, ésta puede y ha sido utilizada por los candidatos políticos al intentar responder a supuestas acusaciones o ataques provenientes de sus adversarios.

Cabe destacar, que la única regla o norma que parece ser consistente o aplicable con respecto a estos comerciales, es que deben ocurrir con rapidez y repetidamente, 
Esta obra forma parte del acervo de la Biblioteca Jurídica Virtual del Instituto de Investigaciones Jurídicas de la UNAM

después del ataque inicial del rival para anular la amenaza antes de que ésta se vuelva viral.

De hecho, la mayor parte de los consultores expertos en medios masivos indican que algún tipo de respuesta a un ataque contenido en un comercial debe ser transmitido tan rápido como sea posible después del ataque inicial, puesto que el público elector será influido por este primer golpe (es una realidad de la naturaleza humana que la mayoría de los electores están siempre dispuestos a creer las peores cosas sobre los políticos).

Por otro lado, se puede establecer que la única instancia bajo la cual un candidato se puede "salir con la suya" sin responder a un ataque, es cuando éste proviene de un candidato intrínsecamente débil (alguien con muy bajo reconocimiento de nombre, sin experiencia previa o con financiamiento inadecuado). Esta regla o norma no escrita entre los teóricos de los comerciales políticos a nivel comparado, es confirmada con la dinámica observada en el debate entre los aspirantes a la Presidencia de la República en México (en 2012); en este sentido, los ataques de Gabriel Quadri jamás tuvieron eco en ninguno de los otros aspirantes restantes ni en el electorado el día de la jornada electoral.

Si bien, un comercial político de respuesta a uno de ataque puede adoptar una variedad de formas, la utilizada con mayor frecuencia es aquella que emplea (a) una estrategia de refutación o rechazo (un rechazo directo del ataque); (b) una estrategia de contraataque (en lugar de refutar el ataque o acusación, el candidato lanza un ataque ya sea sobre la personalidad, las posiciones sobre los grandes temas nacionales, o los motivos o las acciones de quien a su vez lo atacó), y (c) una estrategia de humor-ridículoabsurdo.

Cabe resaltar, y esto es de gran utilidad en el contexto histórico de la campaña de Francisco Labastida Ochoa en la selección interna del PRI en 1999, que se ha observado cada vez con mayor frecuencia que los comerciales de respuesta no sólo se han incrementado sino que se han producido y transmitido cada vez más rápido que en el pasado.

De esta forma, los consultores o asesores frecuentemente crean y transmiten los comerciales de respuesta dentro de un lapso de horas -ya no de días-y apresuran el proceso mediante la transmisión de dichos comerciales desde satélites enviándolos a estaciones televisoras en áreas específicamente escogidas o incluso colocándolos 
Esta obra forma parte del acervo de la Biblioteca Jurídica Virtual del Instituto de Investigaciones Jurídicas de la UNAM

digitalmente en canales como Youtube.com para anular la presencia de candidatos o posturas marginales que ahí se ventilan con naturalidad.

Ahora bien, una de las razones que justifica el concentrarse en una respuesta rápida, radica en el hecho de que los consultores temen que los comerciales de ataque del adversario logren establecer una especie de control sobre el diálogo o incluso establecer el tenor del diálogo para el resto de la campaña política electoral.

Ya que, aunque en alguna época pasada, y en México hasta muy recientemente, los discursos pronunciados por los candidatos así como los documentos o las ponencias escritas por los mismos constituían la "espina dorsal" para establecer el tenor del diálogo entre contendientes políticos, en años recientes la fuente principal ha sido el comercial de ataque o de respuesta.

Sin duda alguna, las funciones comunicativas más importantes de los llamados "comerciales de respuesta" giran en torno a un intento por establecer el llamado "control de daños" resultante del ataque de un adversario, así como la posibilidad de que su contenido se vuelva "viral" en el mundo del ciberespacio. Específicamente, la respuesta del candidato debe darse y funcionar para "rebotar", y desviar la atención de sujeto del ataque o acusación, para dirigirlo hacia un "terreno seguro" para el propio candidato. De la misma manera, el comercial debe funcionar de manera ideal para colocar nuevamente al candidato a la ofensiva o en una posición de relativa ventaja.

En este sentido, la lección es que el candidato que continuamente debe asumir una posición defensiva rara vez ganará una elección, pues su energía personal y mediática así como las de su equipo de campaña se utilizarán sólo marginalmente en la vertiente positiva de su esfuerzo de campaña, logrando una percepción de debilidad que constituye el "beso de la muerte" en cualquier proceso electoral.

Por otro lado, una de las tesis más interesantes —aunque aún polémicas - creadas en los últimos años en relación con la estrategia y la defensa ante comerciales de ataques, es que la estrategia más efectiva que puede utilizar un candidato para prevenir ataques antes de que los adversarios los lancen: mitigar su eficacia. Específicamente, se ha establecido una clase o tipo de estrategia de prevención llamada entre los expertos estrategia de inoculación de mensaje, (una especie de vacunación que inmuniza ante ataques) que resulta de gran efectividad debido a que no únicamente (a) anticipa y responde el ataque de un adversario antes de que sea iniciado, sino que (b) fortalece "la 
Esta obra forma parte del acervo de la Biblioteca Jurídica Virtual del Instituto de Investigaciones Jurídicas de la UNAM www.juridicas.unam.mx

DOI: http://dx_doi.org/10_22201/iij.24487910e_2015.7.10085

resistencia" (tomando prestados los términos médicos) a la aceptación o creencia en futuros ataques al exponer al elector a una dosis débil del citado ataque. La "dosis débil, reducida o rebajada" es lo suficientemente fuerte para estimular las defensas, pero no tan fuerte que aniquile al candidato de que se trate. Sin embargo, cabe aclarar que este tipo de estrategia preventiva requiere de gran talento discursivo y narrativo por parte del equipo de campaña que diseña la estrategia así como de un dominio de la psicología del poder que evite el desastre que sobreviene con el exceso en la inoculación citada. 